\title{
Sustainable Transport Data Collection and Application: China Urban Transport Database
}

\author{
Tian Jiang, Zhongyi Wu, Yu Song, Xianglong Liu, Haode Liu, and Haozhi Zhang \\ China Urban Sustainable Transport Research Center, China Academy of Transportation Sciences, Ministry of Transport, \\ Beijing 100029, China
}

Correspondence should be addressed to Tian Jiang; peter_zealot@hotmail.com

Received 14 July 2013; Revised 13 October 2013; Accepted 21 November 2013

Academic Editor: Geert Wets

Copyright (C) 2013 Tian Jiang et al. This is an open access article distributed under the Creative Commons Attribution License, which permits unrestricted use, distribution, and reproduction in any medium, provided the original work is properly cited.

Transport policy making process of national and local governments should be supported by a comprehensive database to ensure a sustainable and healthy development of urban transport. China Urban Transport Database (CUTD) has been built to play such a role. This paper is to make an introduction of CUTD framework including user management, data warehouse, and application modules. Considering the urban transport development features of Chinese cities, sustainable urban transport development indicators are proposed to evaluate the public transport service level in Chinese cities. International urban transport knowledge base is developed as well. CUTD has been applied in urban transport data processing, urban transport management, and urban transport performance evaluation in national and local transport research agencies, operators, and governments in China, and it will be applied to a broader range of fields.

\section{Introduction}

With the economy growing rapidly in recent years, the total number of vehicles increases dramatically and leads to urban traffic congestion, environmental pollution, and energy issues. To enhance the level of service for travelling in urban areas, both central and local governments in China have applied suitable strategies and policies to reduce the traffic congestion and air pollution. Public transport has been considered as the most promising way to solve these promising way to solve these problems and is given the priority in urban transport development. The State Council of China, at the beginning of 2013, issued The Guideline on Further Implementing the Prioritized Development of Urban Public Transport, which ensures the leading role of public transit in urban transport.

There are several successful cases of database to provide urban transport data to support policy making, transport planning, and evaluation. Several institutions around the world are working on data collection and sharing. We list online resources of their databases as follows:

(i) http://www.regiolab-delft.nl/ developed by Region Laboratory Delft, Netherlands, (ii) http://safety.fhwa.dot.gov/tools/data_tools/ fhwasa09002/ developed by Federal Highway Administration (FHWA), USA,

(iii) National Household Travel Survey: http://nhts.ornl. gov/,

(iv) http://www.fhwa.dot.gov/policy/ developed by Federal Highway Administration (FHWA), USA,

(v) Online resource as of 2010: http://www.fmcsa.dot. gov/facts-research/facts-figures/analysis-statistics/ dashome.htm,

(vi) Highway Performance Monitoring System: http:// www.nhtsa.gov/Data/,

(vii) http://www.ntdprogram.gov/ntdprogram/ developed by Federal Motor Carrier Safety Administration (FMCSA), USA,

(viii) http://mobility.tamu.edu/ developed by National Highway Traffic Safety Administration (NHTSA), USA,

(ix) http://www.nra.ie/ developed by Federal Transit Administration (FTA), USA,

(x) http://www.astra.admin.ch/, 
(xi) National Transit Database: http://www.uitp.org/ publications/.

Problems exist in the reuse of traffic data, with various data formats, different aggregations, and different densities of metainformation (when existing). Miska et al. (2007) developed an International Traffic Database (ITDb) to deal with these problems by applying data name matching or translation to form a comprehensive standardized data pool, which can improve efficiency of the database $[1,2]$.

ITDb is a database that focuses on collecting and providing urban road traffic data (vehicle speed, traffic volume occupancy, etc.) in cities all over the world to provide help to academic researches or other applications [3,4]. Another US database, the National Transit Database (NTD), which focuses on data collection and application of public transport data, is different from ITDb [5]. The NTD is developed to satisfy the data requirements of all levels of governments and the public. The NTD can evaluate the performance of nation's public transport system and can be used to calculate the amount of public transport system supporting funds. Public transport service quality evaluation cannot be made since daily service data is not collected.

China Transport Statistical Information Network and China Public Transport Network are two nationwide transport databases developed by Chinese companies and transport management agencies. However, the two databases have many inadequacies which cannot meet the needs for urban transport study or other practical application. The following are the current shortcomings of Chinese transport databases.

(i) No comprehensive urban transport database (with data types including urban and suburban, domestic and international, public and private transport, GIS and urban transport, etc.).

(ii) No data uploading and downloading mechanisms.

(iii) No comparative analysis of urban transport data.

(iv) No integrated decision making system.

Since the existing transport databases are either not suitable or comprehensive enough to monitor the development of public transit, evaluate policy effects on urban transport improvements, and support decision making, an integrated database needs to be established specially for sustainable urban transport development [6].

China Urban Transport Database (CUTD) is the first nationwide comprehensive urban transport database, with various types of data such as urban transport network, infrastructure, individual travel, public transport, and pedestrian data. The data sources of CUTD include GIS urban network map, traffic control feedback, traffic monitoring system, public transport operation, and so forth. With abundant and wide-covering urban transport data, CUTD supports decision-making, planning, management, and operation process of urban transport, helping the development of safe, convenient, efficient, economical, equitable, and sustainable urban transport systems for Chinese cities. As a project funded by Volvo Research and Educational Foundations (VREF), CUTD is accessible to partners and colleagues from all VREF Centers of Excellence (CoE).

\section{The Framework of CUTD}

The framework of CUTD includes modules of user management, data warehouse, and application $[7,8]$. Indicators based on Chinese urban transport features are proposed to support transport development policy making and the assessment of development strategies' effects.

The three modules of CUTD: user management, data warehouse, and application (see Figure 1) are designed to realize the database's functions of storing transport data (ranging from raw data to statistical analysis results), running statistical analysis, and making evaluations. Each of the modules is designed and developed independently to focus on both technical aspects and the satisfaction of user demands [9]. The development of CUTD is based on its final operation. To meet the requirement of high performance, CUTD data has to be highly transfer-efficient and be of high quality. Other existing designs of databases, which are simply based on a single set of data types, are different from CUTD.

2.1. User Management. CUTD users include data providers and decision makers. Highway companies, bus and metro operators, and statistic departments of governments are data providers who are required to register the database and upload data regularly. All levels of governments and their supporting research agencies are decision makers who can make use of the data analysis and the evaluation and simulation results to develop transport development strategies. During the data uploading and user processes, the database administrator implements data quality management to ensure good data quality for the proper work of algorithms and tools. All datasets are strictly checked according to the quality management rules, which require a minimum set of metainformation.

Other potential users of CUTD data include domestic and international academic organizations (NGOs, universities, specialists, etc.) and individuals. Different levels right to the database are delivered to different groups of users. The Ministry of Transport of the People's Republic of China establishes a specific network for national and international data exchange and cooperation.

2.2. Data Warehouse. The data warehouse of CUTD includes three layers: geographic layer, transport layer, and data collection layer, which composite a stable and compact structure, improving the robustness of CUTD.

2.2.1. Geographic Layer. Based on GIS maps, the geographic layer provides map information that includes aspects of urban transport network and railway network, as shown by Figure 2. Transport infrastructures are divided into two groups, the link and the node, which can ensure a minimum set of metainformation for the users to search and get access to.

2.2.2. Transport Layer. Unlike the static urban transport structure information stored in the geographic layer, the transport layer of data warehouse consists of comprehensive data of all moving objects in urban transport system, 


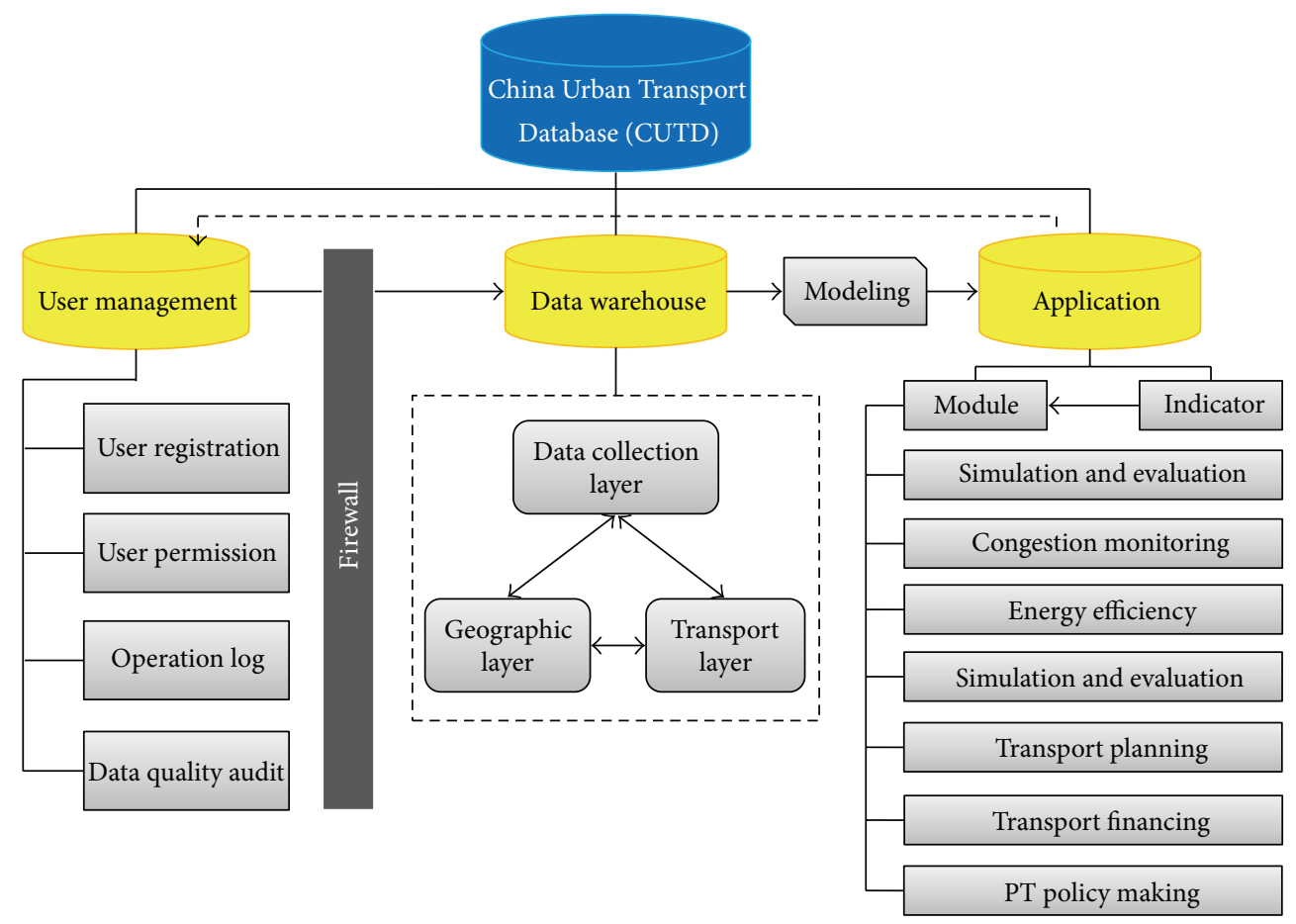

Figure 1: The framework of China Urban Transport Database.

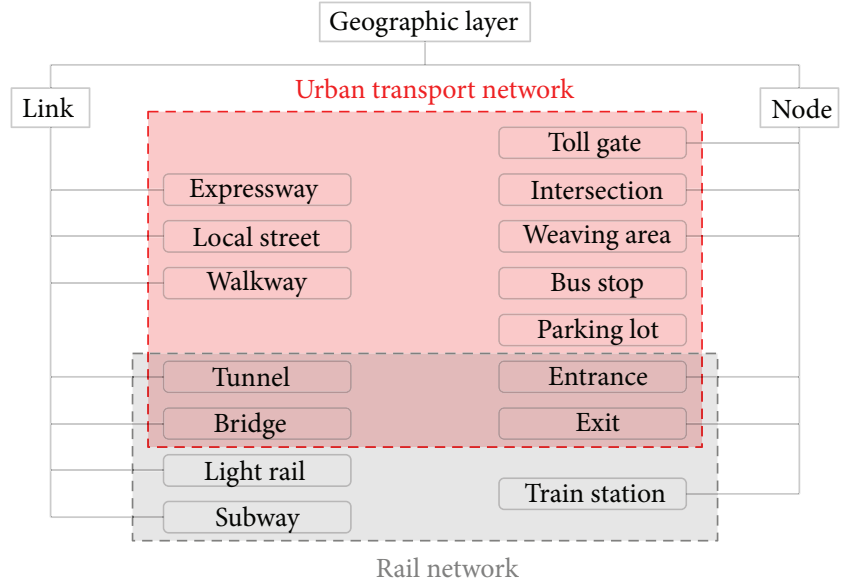

FIGURE 2: Structure of the geographic layer of CUTD.

including cars, buses, trains, motorcycles, bicycles, pedestrians, passengers, and so forth. Information including the original attributes and dynamics describing the movement of objectives are all stored in this layer, as shown by Figure 3.

2.2.3. Data Collection Layer. The data-collection layer consists of real-time traffic data collected by road traffic detection systems, which include the sensor type and location, the penetration rate of probe vehicle, and mobile device information. The collection of this type of data needs the support of roadside detecting equipment, GSM equipment, or vehicleinfrastructure communication equipment. Real-time traffic

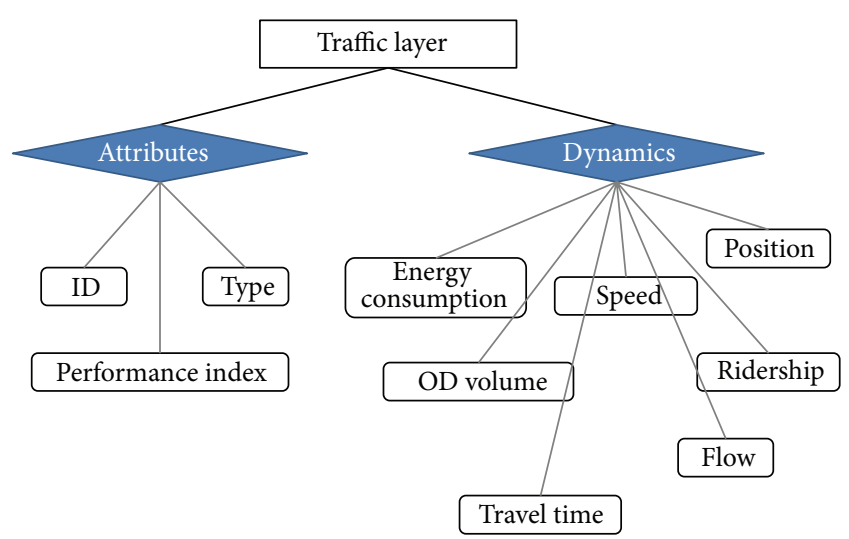

FIGURE 3: Structure of the traffic layer of CUTD.

data can be helpful to online traffic management, intelligent dispatching of public transport modes or taxis.

2.3. Application. The following (including but not limited) are function modules which can be realized based on the data warehouse of CUTD. These modules can support the fulfillment of the urban transport development objectives of CUTD.

(i) Urban traffic simulation and evaluation $[10,11]$. This module can provide simulation of urban traffic conditions (road, urban rail, or pedestrian, etc.) and evaluate traffic conditions. 
(ii) Traffic congestion monitoring and management. This module can dynamically monitor urban road traffic condition and identify congestion links or nodes.

(iii) Energy consumption and emission monitoring and calculation.

(iv) Urban transport planning.

(v) Urban transport investment cost-benefit analysis and public transport enterprises' operation cost-audit and subsidy apportionment.

(vi) Public transport policy making support.

(vii) Travel service information.

\section{China Sustainable Urban Transport Evaluation Indicator System}

3.1. Sustainable Urban Transport Evaluation Indicators. For a certain city, CUTD data can be applied in the assessment of urban transport sustainable level and the evaluation of its public transport performance; therefore, the database plays a significant supporting role in the urban transport policy making process. The application of CUTD data can provide help to all levels of governments to improve their urban transport development strategies and urban transport management approaches.

Sustainable Urban Transportation System (SUTS) is a crucial part of an energy-saving, environment-friendly, and people-oriented society. To make an urban transport development towards SUTS, the evaluation of the sustainability of transport system should be carried out first. Establishing an indicator system for the SUTS is a suitable work to start with $[12,13]$. The evaluation indicator system is preliminarily composed of 6 aspects and 26 indicators as shown in Table 1.

3.2. Public Transport Performance Indicators. Giving priority to urban public transport development has been regarded as a right strategic choice for urban transport development in Chinese cities. The Chinese government has made a plan to build a number of "Transit Metropolis" in the Twelfth FiveYear Transport Development Plan; therefore, the importance of the establishment of a national public transport performance indicator system has appeared. The indicator system can help evaluate and guide the public transport development in Chinese cities.

The following 8 aspects are selected to set indicators for the development of public transport performance indicator systems [14].

(1) Public transport infrastructure performance (e.g., the ratio of bus parking spaces in the station).

(2) Public transport service quality [15] (e.g., the availability indicators, the convenience indicators, the cost indictors, the comfortable indicators, and the safety and security indicators).

(3) Public transport industry economy level (e.g., investment cost-benefit analysis).
TABLE 1: Sustainable urban transport evaluation indicators.

\begin{tabular}{|c|c|}
\hline Aspect & Indicator \\
\hline \multirow{8}{*}{$\begin{array}{l}\text { Transportation } \\
\text { function }\end{array}$} & Road network density $\left(\mathrm{km} / \mathrm{km}^{2}\right)$ \\
\hline & Resident average travel time (min) \\
\hline & Resident average transfer time (min) \\
\hline & Commute time by public transport (min) \\
\hline & Average speed at arterial roads $(\mathrm{km} / \mathrm{h})$ \\
\hline & $\begin{array}{l}300 \mathrm{~m} \text {-radius coverage ratio of public transit } \\
\text { station }(\%)\end{array}$ \\
\hline & Public transit network density $\left(\mathrm{km} / \mathrm{km}^{2}\right)$ \\
\hline & Berths supply-demand ratio (\%) \\
\hline \multirow{6}{*}{$\begin{array}{l}\text { Economic and } \\
\text { financial }\end{array}$} & Infrastructure invest/GDP (\%) \\
\hline & Public transit invest sharing (\%) \\
\hline & Financial subsidies sharing (\%) \\
\hline & $\begin{array}{l}\text { Average annual growth rate of urban transport } \\
\text { investment (\%) }\end{array}$ \\
\hline & Public transport affordability (\%) \\
\hline & Household travel cost $(\%)$ \\
\hline \multirow{6}{*}{ Equity and safety } & Pedestrian path area per capita $\left(\mathrm{m}^{2} /\right.$ person $)$ \\
\hline & Public transport and nonmotor share (\%) \\
\hline & Percentage of villages with PT services (\%) \\
\hline & $\begin{array}{l}\text { Accidental fatalities among 10,000 vehicles } \\
\text { (person/10,000 vehicles) }\end{array}$ \\
\hline & Annual growth rate of major accidents (\%) \\
\hline & Accidental economic loss (Yuan/vehicle) \\
\hline \multirow{3}{*}{$\begin{array}{l}\text { Energy } \\
\text { consumption }\end{array}$} & Fuel consumption per vehicle (liter/vehicle) \\
\hline & Occupier of land (\%) \\
\hline & Traveler volume/road area $\left(\right.$ person $\left./ \mathrm{m}^{2}\right)$ \\
\hline \multirow{2}{*}{$\begin{array}{l}\text { Environmental } \\
\text { influences }\end{array}$} & Pollutant emission per vehicle (gram/vehicle) \\
\hline & Traffic pollution sharing (\%) \\
\hline $\begin{array}{l}\text { Management } \\
\text { capacity }\end{array}$ & Urban transportation management ability \\
\hline
\end{tabular}

(4) Public transport operational level (e.g., transportation efficiency, vehicle-employee ratio, and public transport vehicle number per one million people).

(5) Public transport information service level (e.g., bus intelligent dispatching, electronic bus stop ratio).

(6) Safety and security level (e.g., fatalities per 10,000 vehicles, annual growth rate of major accidents).

(7) Energy saving and emission reduction level (e.g., percentage of bus using clean-energy, fuel consumption per passenger/vehicle).

(8) Public transport industry standardization level (e.g., public transport operation/service standardization, public transport terminology, and glossary standardization).

\section{Data Collection Methods}

CUTD data can be obtained through the following three channels. 
(1) Ministry of Transport (MOT) and Ministry of Finance (MOF) of China issued circular "Urban and Rural Passenger Transport Fuel Subsidy" in the end of 2009. The central government will establish the "Public Transport Development Foundation" in the near future. Referring to the experience of the US National Transit Database (NTD), all fund receivers or all fund applicants might be required to report energy consumption data and public transport development related data (such as public transport investment data, operation data, and maintenance data, etc.) to the nationwide urban transport database.

(2) MOT carries out urban passenger transport statistics every year; therefore, the second data source can be developed by means of urban passenger transport statistics mechanism.

(3) As a tentative plan, cooperation with Chinese cities such as Beijing, Shanghai, Chengdu, Zhengzhou, Jinan, Xi'an, and so forth can provide opportunities to obtain dynamic traffic data and develop the preliminary dynamic data report system. Also, the number of cooperation cities can be increased gradually in the future with the dynamic traffic data report system extended.

\section{CUTD Application Examples}

The application of CUTD has been pushed forward with the building of Urban Transport Planning, Control and Evaluation Lab, within which five systems including Urban Transport Data Collection and Analysis System, Urban Public Transport Intelligent Control and Information Management System, Urban Transport Data Management System, Urban Transport Planning Decision-Making Supporting System, Urban Transport Simulation and Evaluation System, and Urban Public Transport Monitoring Information Platform have been designed.

5.1. Urban Transport Data Collection and Analysis System. This system has two main functions of data collection and data analysis, which serve both data providers and decision makers. As shown by Figure 4, urban transport data is collected from data providers through extraction, cleansing, classification, and loading and imported into CUTD and IUTD (International Urban Transport Database). By analysis and comparison of the data from the two databases, query, statistical analysis, data mining, and information sharing can be realized. Various types of analysis results can then be shown to decision makers (or other data users).

For data providers, this system offers functions of on-page data reporting, spreadsheet uploading, and data approving to improve data input convenience and ensure high data quality. Providers can log into the system and type in data directly on pages as shown by Figure 5 or fill data into standard formatted excel spreadsheets and upload the files onto the system. Uploaded data can be reviewed, modified, or deleted. Data approving function examines the data, stores qualified data for the use by analysis system and monitoring system, and returns unqualified data for modification.

5.2. Urban Public Transport Intelligent Control and Information Management System. This system includes two parts: taxi dispatching and information collection and intelligent bus dispatching and control.

The taxi dispatching and information collection module has functions of monitoring, data converging, and reporting generating. Taxi status monitoring, vehicle positioning, vehicle alarming, and vehicle control can be realized by collecting and managing taxi GPS information, driver information, and vehicle information through this module. These types of information can be integrated into a GIS program, which can display vehicle position and driving route on maps. Information of time, speed, vehicle, driver, and even vehicle monitoring video can also be transmitted and displayed on different interfaces. Taxi dispatching can be compiled by applying various telecommunication measures considering taxi information and the actual operational needs. Figure 6 shows an application of this module in Beijing's taxi dispatching.

The intelligent bus dispatching and control module collects CAN bus information and GPS information and displays the position, speed, schedule following status, and other information of buses on real-time interfaces. This module has been applied in Dalian Development Area. There are three view types of bus operation status: simulation view as shown by Figure 7, track view, and schedule view as shown by Figure 8. Dispatching and managing tasks including arrival, departure, operation, stop, return, and fault can be carried out by reviewing the real-time information and issuing instructions through communication tools integrated with other functions.

At the same time, all types of bus operation data are stored into historical database as spreadsheets or operation log. The data can be reviewed by database users or analyzed by statistical programs.

5.3. Urban Transport Data Management System. Within the information construction process, various operation systems have been developed by different departments according to their own business demands. All those systems are separated from each other without any connection or communication. The Urban Transport Data Management System is built to unify all those databases. The following achievements are reached.

5.3.1. Data Management Specifications. Data storing specification ensures the reliability and integrity of data transfer and realizes the pooling and sharing of data.

Data coding specification provides unified conversion interface and unified storage of multisource data.

Data exchange specification provides standard data coding rules and realizes the data exchange between heterogeneous databases. 

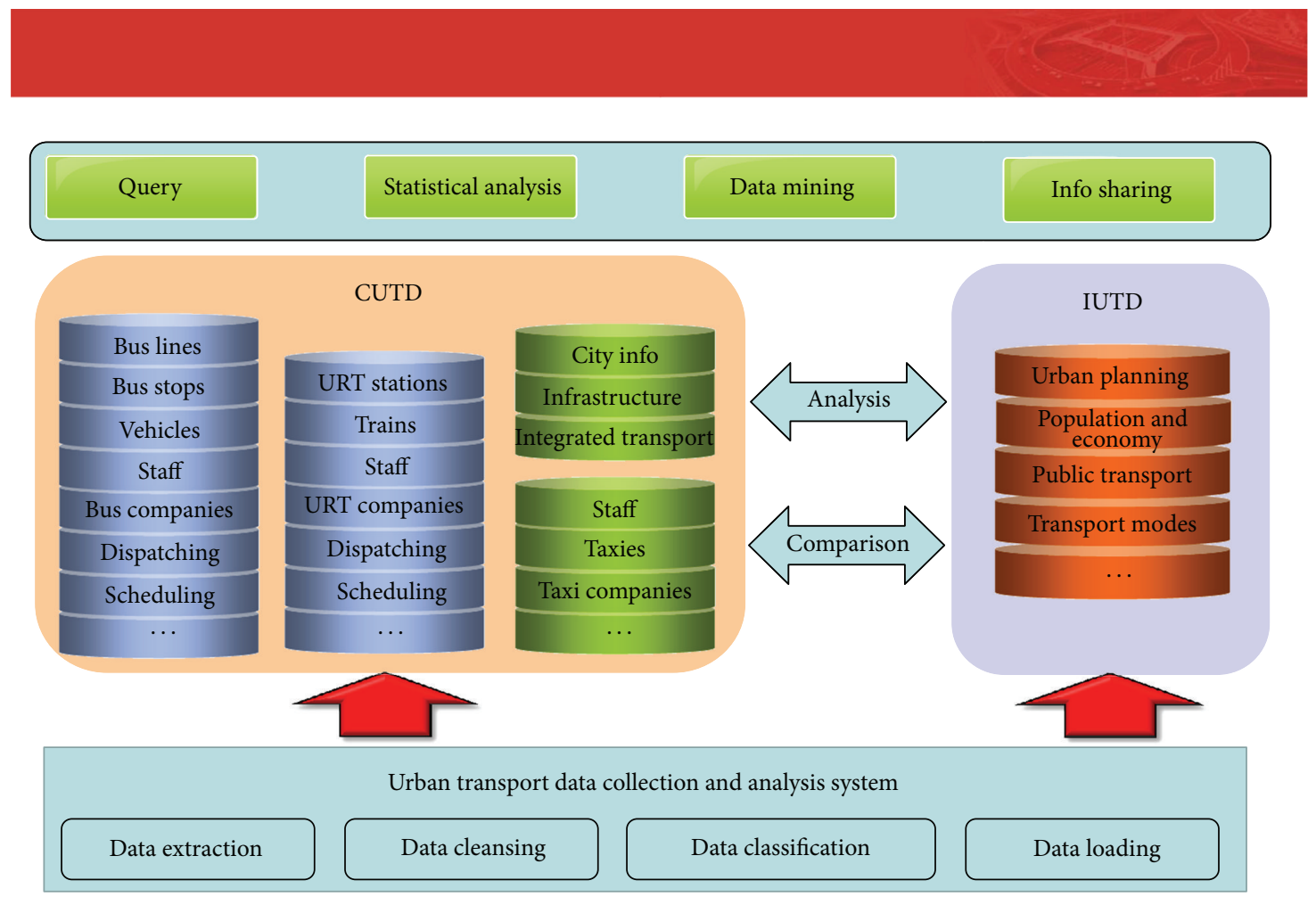

FIgURE 4: The software framework of Urban Transport Data Collection and Analysis System.

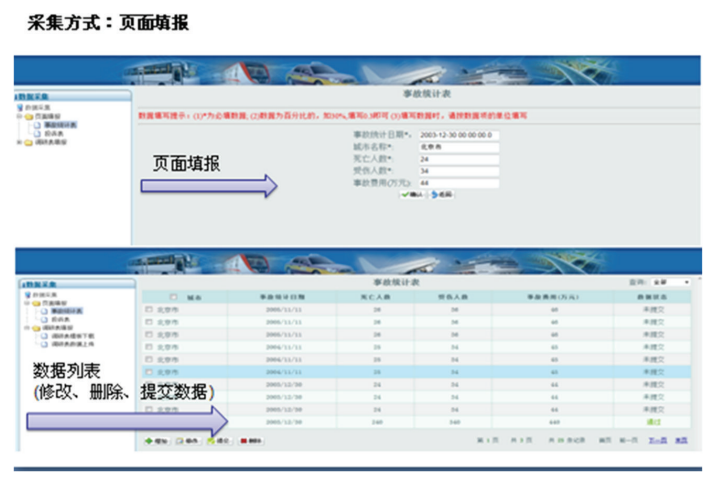

FIGURE 5: On-page data reporting.

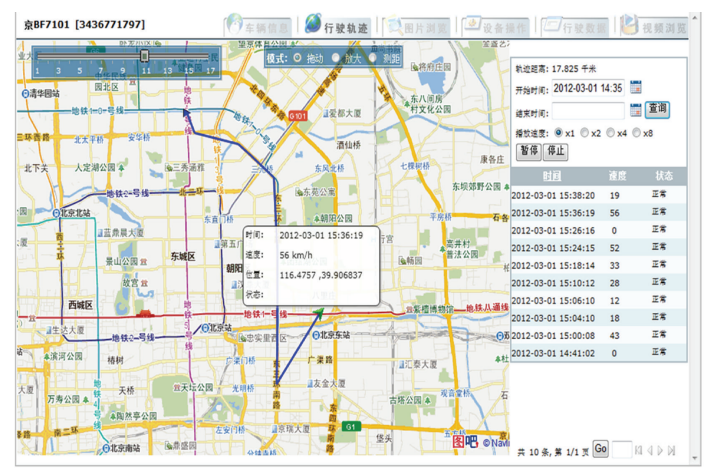

FIGURE 6: Taxi position monitoring based on GIS.

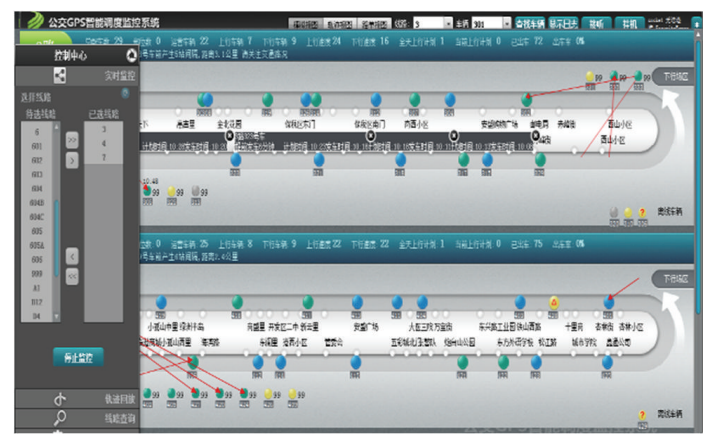

FIGURE 7: Bus operation monitoring and dispatching.

5.3.2. Collection of Domestic and International Urban Transport Data. CUTD has included 58 spreadsheets with over 63.22 million pieces of data.

IUTD has included 51 spreadsheets with over 0.80 million pieces of data.

Also, 0.974 million pieces of abnormal data have been cleaned and filtered.

CUTD data collections include the following.

(i) Dynamic collection of real-time bus and taxi dispatching data.

(ii) Exchange of data from domestic statistical information platform. 


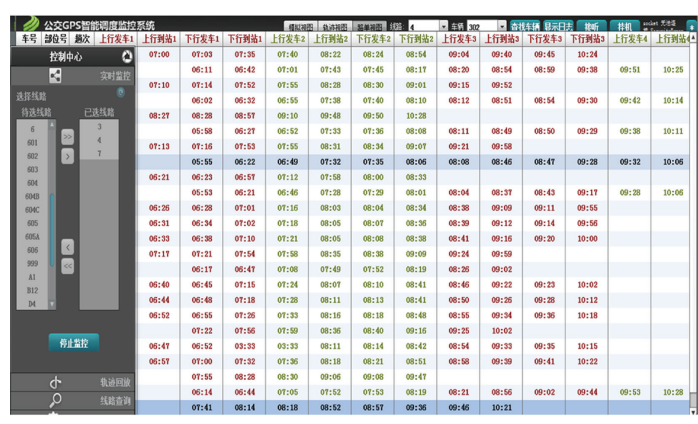

FIGURE 8: Bus schedule following status.

(iii) Collection of data from mastered basic researches and original surveys.

(iv) Collection of relevant data from surveys in typical cities.

(v) Collection of relevant data from surveys in transport enterprises.

(vi) Collection of relevant result data from special surveys in cities by transport management departments.

(vii) Collection of historical data (from urban transport yearbooks or transport yearbooks).

(viii) Collection of fuel consumption data of urban-rural passenger transport and rural water passenger transport.

Classifications of IUTD data include the following.

(i) Collection of data from basic researches.

(ii) Collection of relevant result data from surveys in cities.

5.3.3. A Unified Data Interface for Planning, Simulation, Monitoring, and Evaluation. By developing the functions of data sharing and exchanging, a unified data interface for planning, simulation, monitoring, and evaluation is provided [16]. As shown in Figure 9, the Urban Transport Data Management System can realize four main functions including basic data element management, information resource menu management, data exchange management, and authorization management.

5.4. Urban Transport Planning Decision-Making Supporting System. This system has four models providing evaluation data for urban development indicators, public transport service quality, and future planning to support transport planning decision-making.

5.4.1. Urban Public Transport Planning Model. By analyzing basic travel information (collected from daily travel survey and bus passenger survey) and geospatial information (including bus geographic data and socioeconomic data) from urban transport database, this model can achieve travel plan analysis, bus corridor classification, bus line planning, public transport optimization program design, and public transport program review to support decision-making by public transport managers.

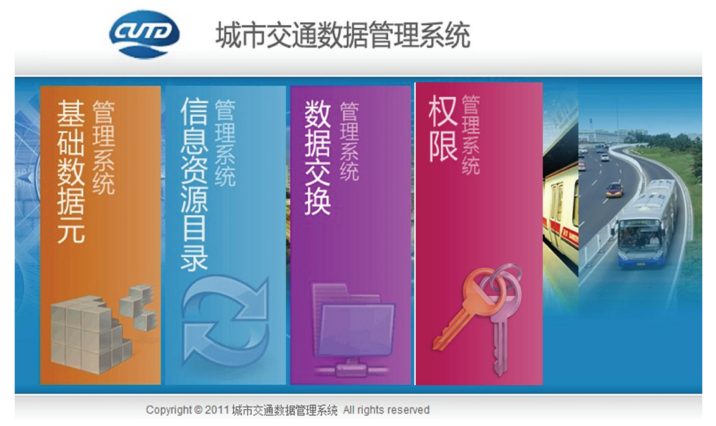

FIgURE 9: The interface of Urban Transport Data Management System.

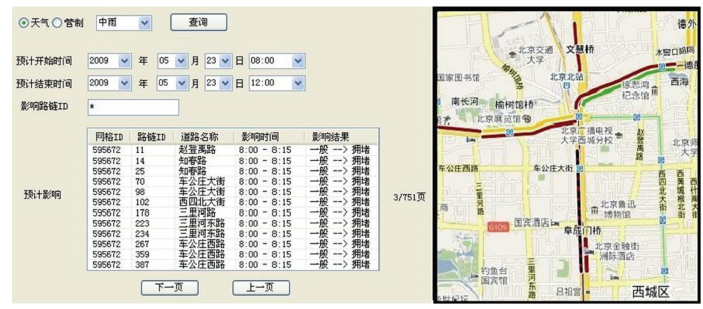

FIGURE 10: Congestion status display.

5.4.2. Transport Infrastructure Investment-Benefit Analysis Model. By using operation scheduling, real-time dispatching, infrastructure, and other data and carrying out subsidy test [17], passenger traffic calculation, and other data mining technology to get investment-benefit and traffic operation benefit information, which provide dynamic parameters for evaluation and display. This model can achieve the comparison of different transport infrastructure investment options (e.g., the comparison between tram and BRT) to provide references to governors or investors on decision-making.

5.4.3. Urban Traffic Congestion Analysis Model. By carrying out floating car data map matching and calculation, combined with path speculation, traffic trend judgment, feature fusion, and other data processing measures, this model can provide traffic conditions and the average speed of buses. This model has been applied in the congestion analysis of Beijing. Congestion levels are displayed on road maps as shown by Figure 10. Congestion data including influencing time, period, and results is stored in congestion database.

5.4.4. Urban Transport Energy Environmental Policy Evaluation Model. By using vehicle and operation data from the urban transport database, energy consumption and emission can be calculated to provide support to the evaluation of transport energy and environmental policies.

Functions of this model include the following.

(i) Urban transport energy demand scenario analysis and forecast.

(ii) Urban transport emission scenario analysis and forecast. 


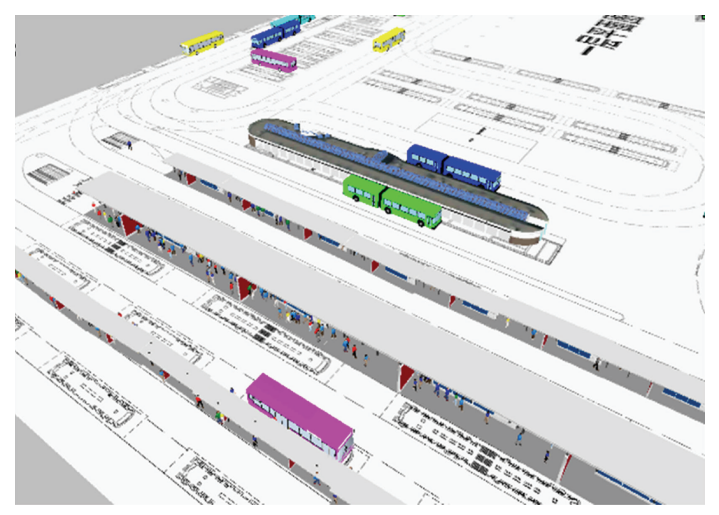

FIgURE 11: A simulation of a public transport hub.

(iii) Evaluation of transport development impacts on future urban environment.

(iv) Evaluation of urban transport impacts on health.

(v) Estimation of vehicle and operation line energy consumption.

(vi) Emission hot spot analysis.

(vii) Evaluation of energy saving and emission reduction effects.

5.5. Urban Transport Simulation and Evaluation System. This system includes urban road network simulation and evaluation model and public transport service quality evaluation model.

\subsubsection{Urban Road Network Simulation and Evaluation Model.} This model is based on microsimulation software, VISSIM, which can realize the simulation of traffic status at different types of road sections and junctions under different control types, different signal timing, different speed limits, or different deceleration controls. The model can get relevant data (infrastructure and transport user data) from urban transport database and apply the data in simulation model construction and model calculation. Outputs of this model are values of evaluation indicators and $3 \mathrm{D}$ simulation video which can show the simulated traffic condition vividly and intuitively.

One of the applications of this model is simulation and evaluation of public transport hubs, as shown by Figure 11. Both the move of public transport vehicles and the move of passengers are simulated. By inputting different groups of vehicle and passenger data, different usage statuses can be demonstrated and different indicator values can be obtained to do evaluations. Also, infrastructure data can be modified to meet different operation and travel demands, as a simulation of infrastructure design or transformation. Evaluations and comparisons of different designs can then be carried out.

\subsubsection{Public Transport Service Quality Evaluation Model.} This model can dynamically correlate index system and bus operation database to make trend analysis of various indicators and comprehensively evaluate urban public transport

\begin{tabular}{|c|c|c|c|c|}
\hline 签轵各 & in & 评分 & 挷各 & 誩标神明 \\
\hline 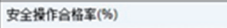 & 0.9615 & 88.30 & - & 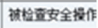 \\
\hline 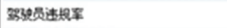 & 0.00576 & 100.00 & - & 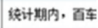 \\
\hline 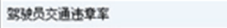 & 0.002438 & 92.60 & - & 看计朋内, 百车 \\
\hline 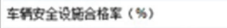 & 0.85 & 68.30 & - & 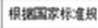 \\
\hline 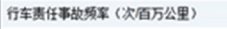 & 0.4359 & 100.00 & - & 级计知内, 行车 \\
\hline 安全适行间聂里虽 (百万公里㐸) & 2.38 & 100.00 & - & 公井垱电轱的 \\
\hline 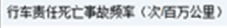 & 0.041 & 64.50 & - & 终计腤内, 行车 \\
\hline 蓇仿水平 (人百万公里) & 0.43 & 81.75 & - & 终计期内, 公共 \\
\hline 西水平 (人百万公里) & 0.041 & 64.50 & - & 络计期内. 公井 \\
\hline
\end{tabular}

FIGURE 12: Operation safety indicators scoring of Zhengzhou Bus Company.

development level by weighting the indexes. Figure 12 shows the operation safety indicators scoring of Zhengzhou Bus Company. Except for the scoring of safety indicators, from the interface it can be seen that there are also scoring of convenience indicators, comfort indicators, reliability indicators, satisfaction indicators, and energy saving (environmental) indicators.

5.6. Urban Public Transport Monitoring Information Platform. In response to the national public transport development priority strategy and a series of regulatory strategies, as well as guidelines and guidance of the Ministry of Transport, surveys and expert discussions were carried out in Chengdu, Xi'an, Zhengzhou, and Shanghai. The Urban Public Transport Monitoring Information Platform was designed and developed. Monitoring of urban public transport infrastructures, passenger traffic, operation smoothness, and security and emergency responding is realized by collecting and analyzing bus and urban rail transport data. Evaluation of urban public transport development is made according to the Urban Public Transport Development Indicator System. Strong support is provided to promote the national "Public Transport City" demonstration construction projects.

5.6.1. Urban Public Transport Development Evaluation. By pooling static data and dynamic data, obtaining data with statistical measures, and making comparisons with the data a year earlier, macrojudgment of urban transport situations can be made. This function can assist the evaluation of traffic management program implementation effects and provide data supports to the exploration of the interaction law between different departments.

\subsubsection{Bus}

Infrastructure Monitoring. By monitoring infrastructure, the development of public transport lines, stations, and vehicles can be mastered and support can be provided to the monitoring and evaluation of urban public transport development, and the strategic development planning decisions. Also, policy support can be provided to further strengthen infrastructure construction.

In terms of vehicles, vehicle type distribution (e.g., newenergy vehicle percentage, and vehicle age distribution) and indicators such as bus unit number per 10 thousand people 


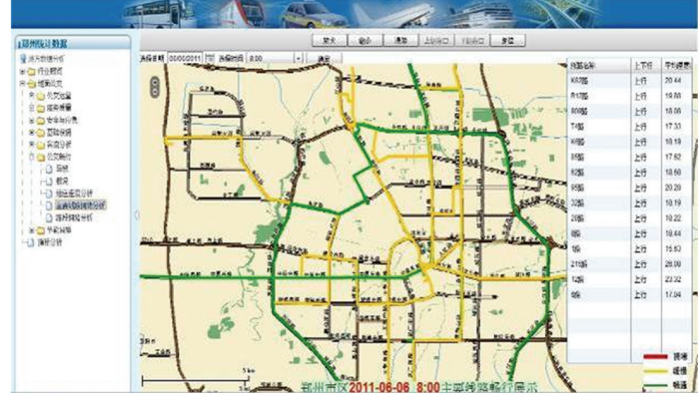

Figure 13: Congestion level of a major bus line network in Zhengzhou.

are counted to support the acquisition and maintenance of vehicles by bus companies.

Passenger Traffic Analysis. The passenger traffic analysis module analyzes the spatial and temporal distribution of urban passengers and is used to guide bus line and bus stop planning and the dispatching coordination of bus operators.

(i) As the most basic indicators, passenger density and distribution are analyzed to provide basic data for hot spot analysis, congestion analysis, and bus corridor building.

(ii) Main stop load factor reflects the distribution of passengers waiting at bus stops.

(iii) Key bus line passenger distribution provides data support to transport planning and bus dispatching coordination.

Public Transport Monitoring. Making use of the research achievement of congestion model, the real-time matching of bus GPS data with nearly 80,000 lines' data and nearly $12,000,000$ pieces of IC card data, the analysis of key bus line operation can be realized based on GIS.

By monitoring bus passenger flows during different periods in morning peaks and evening peaks, the system can analyze the spatial and temporal distribution of bus passengers between key areas and find out big passenger flows between key areas. The system can also evaluate and describe congestion level of road network and bus line network based on road grade and bus speed, as what was applied in Zhengzhou shown by Figure 13.

Energy Saving and Emission Reduction. Bus energy consumption monitoring system analyzes vehicle energy consumption, $\mathrm{CO}_{2}$ emission, intensity, fuel consumption structure, and vehicle type structure according to emission standards. It plays an important role in helping understand the energy consumption, operation, and energy saving of transport system. Effective monitoring and statistics of vehicle emission is the basic measure to reduce pollution, save energy, and reduce emission. It can also lay the foundation for future

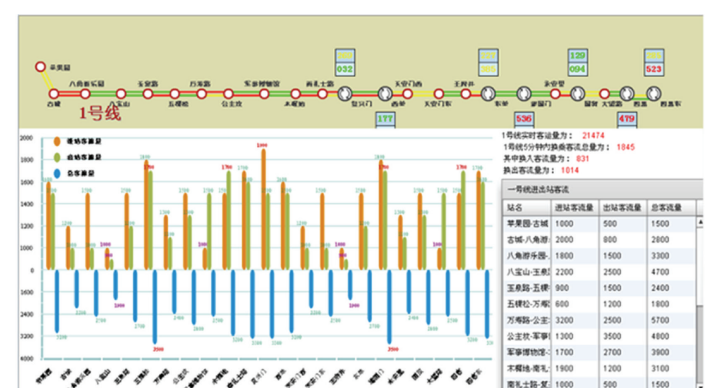

FIGURE 14: Dynamic subway passenger data demonstration.

research on urban transport energy and greenhouse gas emission reduction.

Security and Emergency Responding. The monitoring of security and emergency responding focuses on enterpriselevel indicators including the number of over speed alarm, abnormal brake alarm, abnormal door switch alarm, and accidents.

5.6.3. Urban Rail Transport. In line level, by real-time monitoring and comparing passenger entering and exiting stations, passenger flow direction and moving trend can be dynamically demonstrated in forms of vector charts, stacked charts, and detailed statistics. Figure 14 shows the passenger data of Beijing Subway Line 1. The entering, exiting, and total passenger volumes are demonstrated in the form of a histogram. Passenger flow levels are displayed by different colors on the line map.

Based on urban rail passenger sorting model, key indicators (e.g., line load factor) are analyzed, by fine-grained monitoring of passenger traffic in each direction and each station.

\section{Conclusion and Future Work}

In this paper we have introduced China Urban Transport Database, a user-oriented platform for policy makers. This study has proposed an indicator system of Sustainable Urban Transportation System tailored for the current situation of urban development in China. The results of this study provide the evaluation basis for sustainable urban transportation in China. CUTD will be the primary source of information and statistics on the urban transportation systems of China, serving to improve China's sustainable urban transport development.

As a three-year project, the platform has been established in 2011 based on the framework proposed. Functions of simulation and evaluation, congestion monitoring, energy efficiency, transport planning, and public transport policy making have been implemented by corresponding systems. However, transport financing function is still waiting to be realized; databases still need to be expanded and improved; communications between different systems need to be strengthened. It is also important to improve the applicability of the various indicators, the scientific and operability of the 
weight of each indicator, so greater adaptability is needed for the next stage of the study.

\section{Conflict of Interests}

The authors declare that there is no conflict of interests regarding the publication of this paper.

\section{Acknowledgment}

China Urban Transport Database is funded by the Volvo Research and Educational Foundations (VREF).

\section{References}

[1] M. P. Miska, M. Kuwahara, and S. Tanaka, "Online platform for sustainable traffic data storage," in Proceedings of the 12th World Conference on Transport Research, Lisbon, Portugal, July 2010.

[2] M. P. Miska, A. Torday, H. Warita, and M. Kuwahara, "International traffic database - gathering traffic data fast and intuitive," in Traffic Data Collection and Its Standardization, J. Barceló and M. Kuwahara, Eds., vol. 144 of International Series in Operations Research \& Management Science, Springer, Berlin, Germany, 2010.

[3] M. P. Miska, A. Torday, H. Warita, and M. Kuwahara, "The international traffic database project," in Proceedings of the ITS World Congress, Beijing, China, 2007.

[4] J. Barceló, M. P. Kuwahara, and M. Miska, "Traffic data availability and its standardization," in Traffic Data Collection and Its Standardization, J. Barceló and M. Kuwahara, Eds., vol. 144 of International Series in Operations Research \& Management Science, Springer, Berlin, Germany, 2010.

[5] U. S. Department of Transportation, Traffic Detector Handbook, vol. 2 of Federal Highway Administration Report No: FHWAHRT-06-139, U.S. Department of Transportation, 3rd edition, 2006.

[6] H. Guo, W. Wang, W. Guo, X. Jiang, and H. Bubb, "Reliability analysis of pedestrian safety crossing in urban traffic environment," Safety Science, vol. 50, no. 4, pp. 968-973, 2012.

[7] W. Wang, W. Zhang, H. Guo, H. Bubb, and K. Ikeuchi, "A safetybased approaching behavioural model with various driving characteristics," Transportation Research C, vol. 19, no. 6, pp. 1202-1214, 2011.

[8] J. A. Black, A. Paez, and P. A. Suthanaya, "Sustainable urban transportation: performance indicators and some analytical approaches," Journal of Urban Planning and Development, vol. 128, no. 4, pp. 184-209, 2002.

[9] V. Pina and L. Torres, "Analysis of the efficiency of local government services delivery. An application to urban public transport," Transportation Research A, vol. 35, no. 10, pp. 929944, 2001.

[10] M. G. Karlaftis and P. S. Mccarthy, "Subsidy and public transit performance: a factor analytic approach," Transportation, vol. 24, no. 3, pp. 253-270, 1997.

[11] B. C. Richardson, "Sustainable transport: analysis frameworks," Journal of Transport Geography, vol. 13, no. 1, pp. 29-39, 2005.

[12] H. Gudmundsson, "Making concepts matter: sustainable mobility and indicator systems in transport policy," International Social Science Journal, vol. 55, no. 176, pp. 199-217, 2004.
[13] Y. Tyrinopoulos and C. Antoniou, "Public transit user satisfaction: variability and policy implications," Transport Policy, vol. 15 , no. 4, pp. 260-272, 2008.

[14] H. Castillo and D. E. Pitfield, "ELASTIC-a methodological framework for identifying and selecting sustainable transport indicators," Transportation Research D, vol. 15, no. 4, pp. 179$188,2010$.

[15] A. A. Rassafi and M. Vaziri, "Sustainable transport indicators: definition and integration," International Journal of Environmental Science and Technology, vol. 2, no. 1, pp. 83-96, 2005.

[16] C. Kennedy, E. Miller, A. Shalaby, H. MacLean, and J. Coleman, "The four pillars of sustainable urban transportation," Transport Reviews, vol. 25, no. 4, pp. 393-414, 2005.

[17] K. J. Dueker and J. A. Butler, "A geographic information system framework for transportation data sharing," Transportation Research C, vol. 8, no. 1-6, pp. 13-36, 2000. 


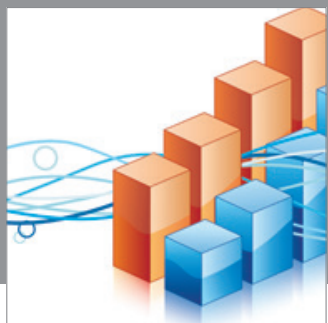

Advances in

Operations Research

mansans

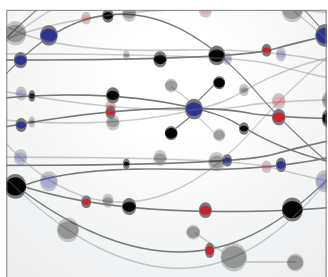

The Scientific World Journal
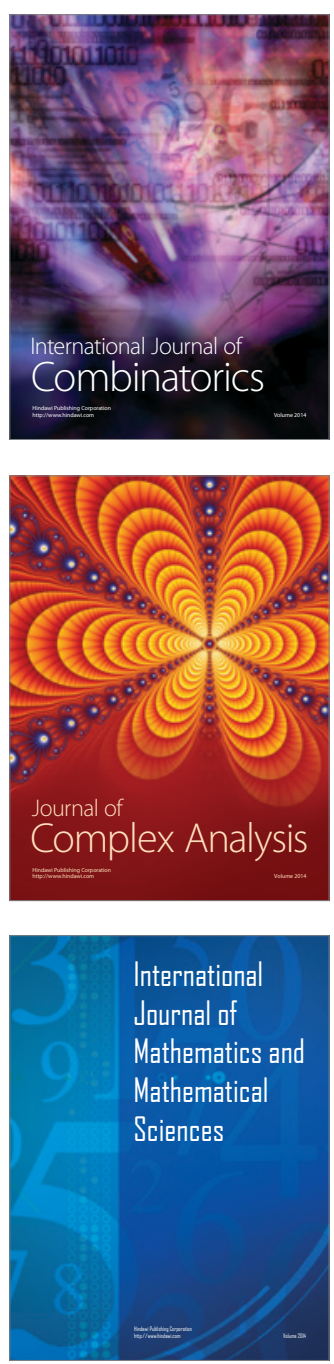
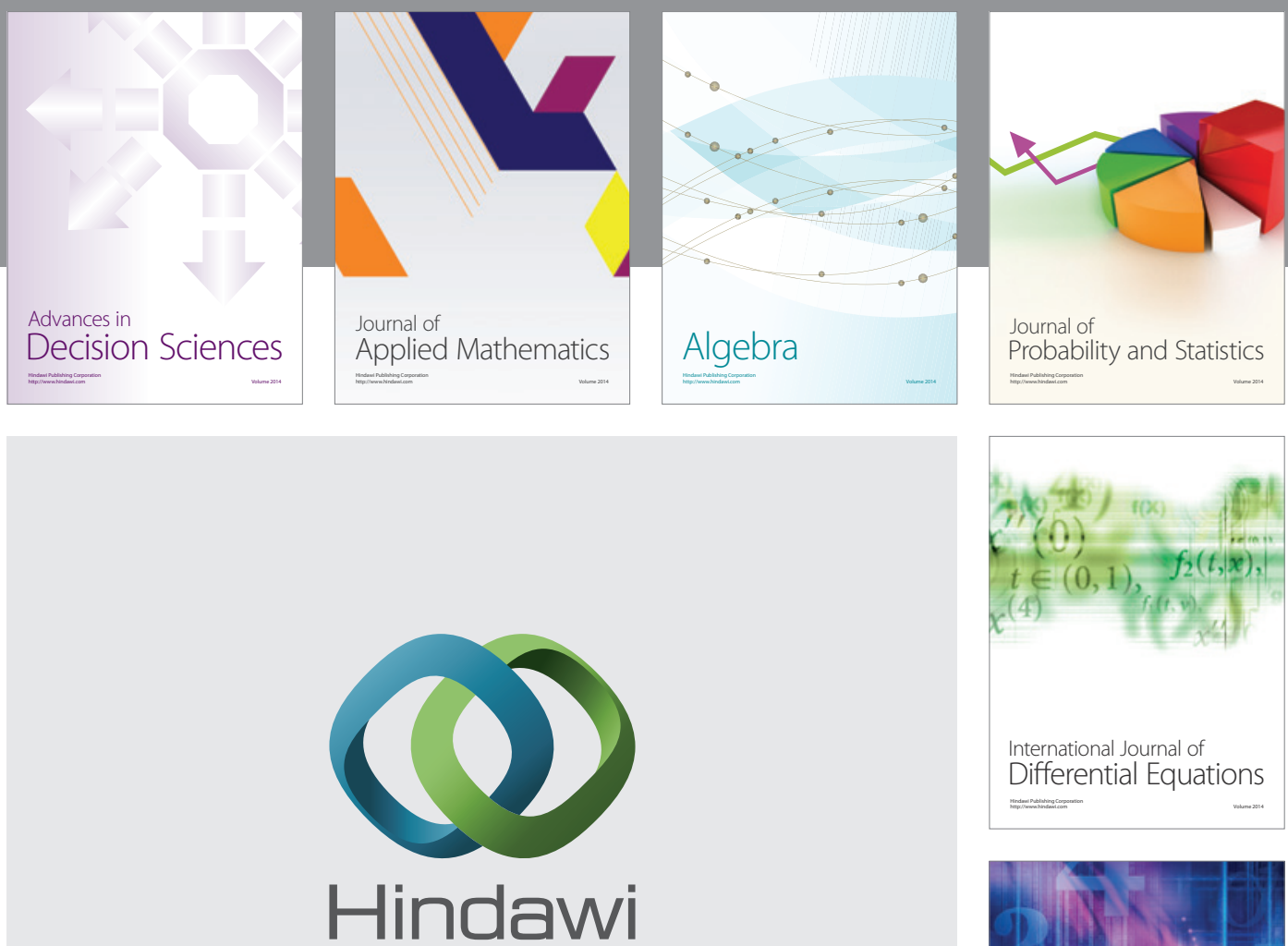

Submit your manuscripts at http://www.hindawi.com
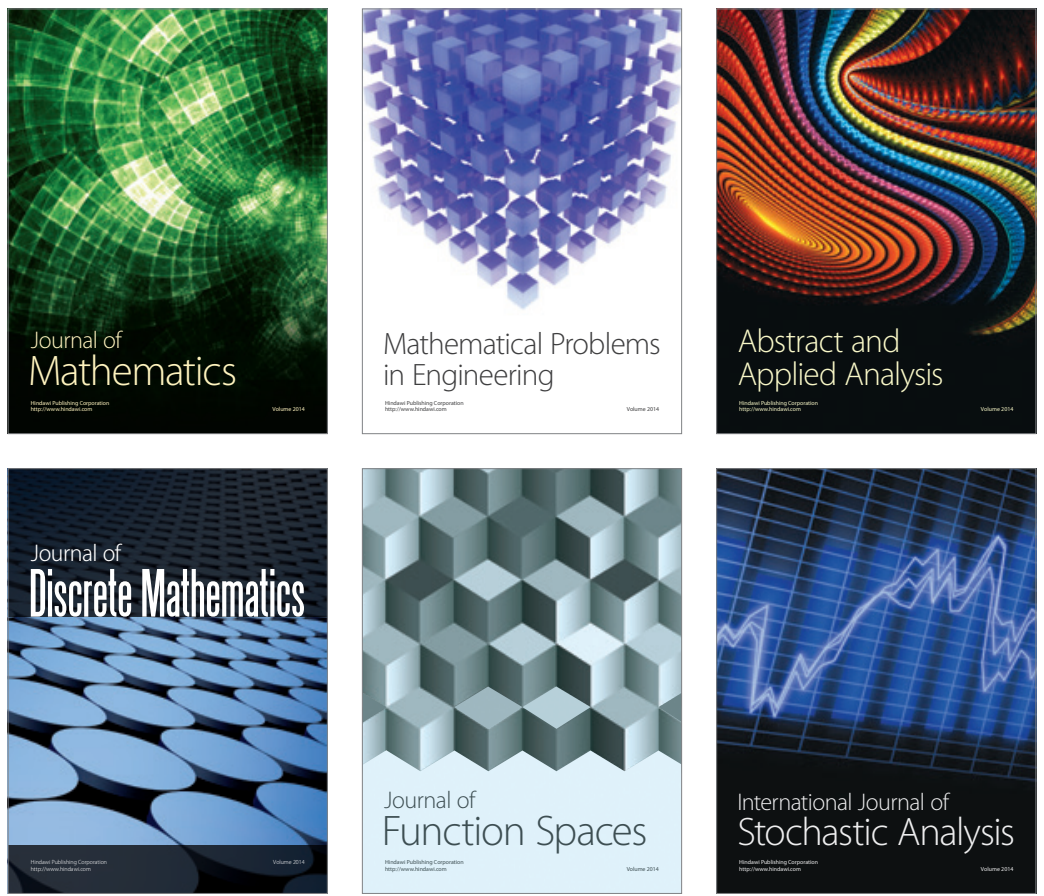

Journal of

Function Spaces

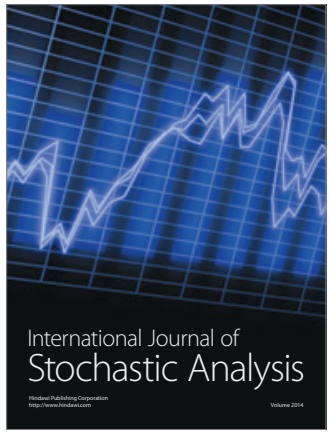

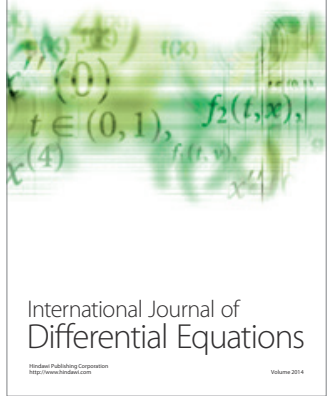
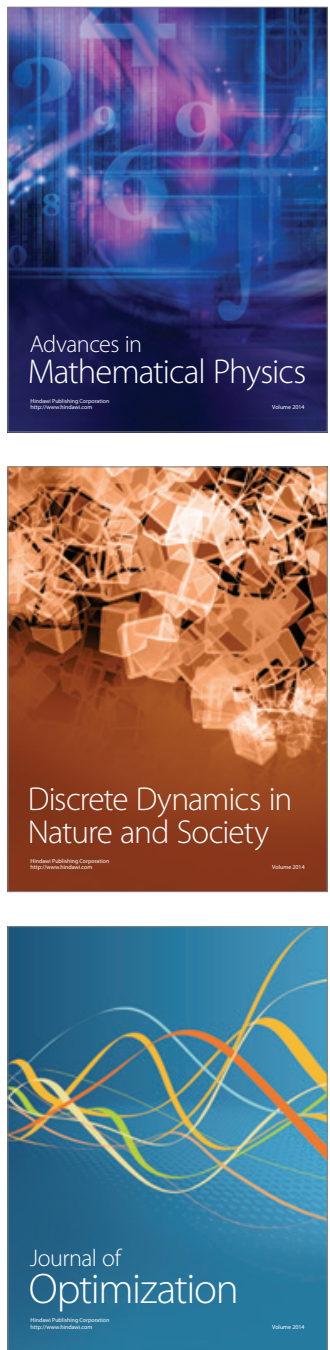